Management international

International Management

Gestiòn Internacional

\title{
Boundary Objects as the Missing Link in the Orchestration of Resources: An Exploratory Study of Dassault Aviation Mirage IV and Rafale Programs
}

\section{Les objets frontières comme lien manquant dans l'orchestration des ressources : une étude exploratoire des programmes Mirage IV et Rafale de Dassault Aviation \\ Los objetos frontera como eslabón perdido en la organización de recursos: Un estudio exploratorio de los programas Mirage IV y Rafale de Dassault Aviation}

David W. Versailles et Valérie Mérindol

Volume 23, numéro 4, 2019

Comprendre les capacités dynamiques : la perspective des micro-fondations

Understanding Dynamic Capabilities: The Microfoundations Perspective

Entendiendo las Capacidades Dinámicas: la perspectiva de las microfundaciones

URI : https://id.erudit.org/iderudit/1066072ar

DOI : https://doi.org/10.7202/1066072ar

Aller au sommaire du numéro

Éditeur(s)

HEC Montréal

Université Paris Dauphine

ISSN

1206-1697 (imprimé)

1918-9222 (numérique)

Découvrir la revue

Citer cet article

Versailles, D. W. \& Mérindol, V. (2019). Boundary Objects as the Missing Link in the Orchestration of Resources: An Exploratory Study of Dassault Aviation Mirage IV and Rafale Programs. Management international / International Management / Gestiòn Internacional, 23(4), 102-117.

https://doi.org/10.7202/1066072ar

\section{Résumé de l'article}

Dans cette contribution, nous analysons l'utilisation des objets frontières (Star et Griesemer) dans l'orchestration des ressources (Teece). Nous proposons une étude de cas comparative de deux programmes d'avions de combat de Dassault Aviation dans le cadre d'une approche abductive. Nous nous situons dans une approche par les micro-fondations. Nous discutons plusieurs propriétés des objets frontières dans le cadre de l'orchestration des ressources : type, granularité, ouverture, malléabilité, et complétude. Notre conclusion indique que les objets frontières jouent un rôle critique pour l'orchestration des ressources. Ces propriétés ont des impacts différents sur les trois aspects du " sensing ", " seizing » et « reconfiguring ». Nous mettons en évidence que les aspects les plus importants concernent l'articulation de la connaissance et le travail en équipe, ainsi que de nouvelles modalités de travail.
Tous droits réservés @ Management international / International Management / Gestión Internacional, 2019
Ce document est protégé par la loi sur le droit d'auteur. L'utilisation des services d’Érudit (y compris la reproduction) est assujettie à sa politique d'utilisation que vous pouvez consulter en ligne.

https://apropos.erudit.org/fr/usagers/politique-dutilisation/ 


\title{
Boundary Objects as the Missing Link in the Orchestration of Resources: An Exploratory Study of Dassault Aviation Mirage IV and Rafale Programs*
}

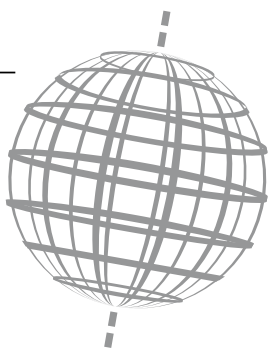

\author{
Les objets frontières comme lien manquant dans l'orchestration \\ des ressources : Une étude exploratoire des programmes Mirage \\ IV et Rafale de Dassault Aviation
}

\section{Los objetos frontera como eslabón perdido en la organización de recursos: Un estudio exploratorio de los programas Mirage IV y Rafale de Dassault Aviation}

\author{
DAVID W. VERSAILLES \\ newPIC chair, Paris School of Business
}

\author{
VALERRIE MERINDOL \\ newPIC chair, Paris School of Business
}

\section{ABSTRACT}

In this contribution, we investigate the use of boundary objects (Star and Griesemer) for the orchestration of resources (Teece). We propose a comparative case study elaborating on two Dassault Aviation military fighters under an abductive approach. In this contribution, we elaborate on the microfoundations approach. Our contribution discusses several properties of boundary objects in relation with the orchestration of resources: type, granularity, openness, malleability, and completeness. We conclude that boundary objects are critical to orchestration. Their properties explain why they diversely impact on sensing, seizing and reconfiguring. They elaborate on knowledge articulation and teamwork, and require specific ways of working.

Keywords: Dynamic capabilities, orchestration of resources, knowledge, articulation, boundary objects, micro-foundations

\section{RÉSUMÉ}

Dans cette contribution, nous analysons l'utilisation des objets frontières (Star et Griesemer) dans l'orchestration des ressources (Teece). Nous proposons une étude de cas comparative de deux programmes d'avions de combat de Dassault Aviation dans le cadre d'une approche abductive. Nous nous situons dans une approche par les micro-fondations. Nous discutons plusieurs propriétés des objets frontières dans le cadre de l'orchestration des ressources : type, granularité, ouverture, malléabilité, et complétude. Notre conclusion indique que les objets frontières jouent un rôle critique pour l'orchestration des ressources. Ces propriétés ont des impacts différents sur les trois aspects du «sensing», «seizing» et « reconfiguring». Nous mettons en évidence que les aspects les plus importants concernent l'articulation de la connaissance et le travail en équipe, ainsi que de nouvelles modalités de travail.

Mots-Clés : Capacités dynamiques, orchestration des ressources, connaissance, articulation, objets frontières, micro-fondations

\section{RESUMEN}

En esta contribución analizamos la utilización de los objetos frontera (Star y Griesemer) para la organización de recursos (Teece). Proponemos un estudio de caso comparativo de dos programas de aviones de combate de Dassault Aviation en el marco de una aproximación abductiva, situándonos en el enfoque de las microfundaciones. Analizamos varias propiedades de los objetos frontera en relación a la organización de recursos: tipo, granularidad, apertura, maleabilidad y completitud. Nuestra conclusión indica que los objetos frontera juegan un papel crítico para la organización de recursos. Vemos como sus propiedades hacen que afecten de manera distinta los tres aspectos de "sensing", "seizing" y "reconfiguring". Mostramos también que sus efectos más importantes se producen a nivel de articulación del conocimiento y trabajo en equipo, así como en nuevas modalidades de trabajo.

Palabras Clave: Capacidades dinámicas, organización de recursos, conocimiento, articulación, objetos frontera, microfundaciones. he concept of dynamic capabilities (Teece and Pisano, 1994)
has developed as a key dimension in management science
for the twofold investigation of innovative capacities and of
competitiveness. Sapienza et al. (2006) explain that dynamic
capabilities represent organizational and strategic routines "by which managers alter their firms' resources through acquiring, shedding, integrating, and recombining resources to generate new value creating strategies". The acquisition of dynamic capabilities pictures the capacity for continuous reconfiguration suited to quickly alignment with the environment (Teece, 2000, 2007).

* Acknowledgements: This research was initiated when the authors were positioned in the French Ministry of Defense, first in the Directorate for Financial affairs, and then in the French Air Force. Special thanks to Ingenieur general de l'armement Bruno Berthet (DGA), to Ingénieur Général Gonin (DGA), to General Jean-Serge Schneider (Fr AF), to General Xavier Jarry (Fr AF) and M. Lionel de la Sayette (Dassault Aviation). This research would have been impossible without their support. We would like to thank the COMAERO team at the Centre d'études d'histoire de l'armement (DGA/CHEAr), the GUERR'ELEC association and the Service historique de l'Armée de l'air (SHAA), which provided with documentation and fruitful contacts. Our gratitude goes to all interviewees who directly contributed to this project: DGA, Air Force and Navy pilots and engineers; and industry executives, engineers and test pilots who interacted with us during interviews and experts groups.

Liability reserve: Ideas expressed in this article are those of the authors and neither commit the French Ministry of Defense nor the French Air Force. Le contenu de cet article n'engage que les auteurs et ne représente en rien les idées du ministère français de la Défense ou de l'Armée de l'air (France). 
The orchestration of resources implies the capacity of coordination inside and outside the boundaries of the firms (Teece, 2007; Adner and Kapport; 2010). Surprisingly enough, the coordination process and the ways of working towards the orchestration of resources are underinvestigated. Some publications (e.g. Kor et al. 2013, Augier and Teece, 2009) have focused on how the interactions between top and middle managers contribute to the orchestration of resources. Others analyze how technologies and platforms contribute to the orchestration. Schneckenberg et al. (2015) analyze how technologies and platforms might facilitate the creation (or the integration) of knowledge and the learning process but we still do not know how platforms and technologies affect the coordination between managers when they operate the "sensing", "seizing" and "reconfiguring".

The goal of this paper is to understand the role of boundary objects (Star and Griesemer, 1989; Fong et al, 2007a, 2007b) in the orchestration of resources. Boundary objects were introduced by Star and Griesemer (1989) as objects "flexible enough to adapt to local needs and the constraints of the stakeholders using them". Boundary objects have different meanings in different contexts, yet they always contribute to improving the interactions by "means of translation and interpretation" (ibid).

In this article, we expect to contribute to understanding how such technological artifacts contribute to coordination in a dynamic capabilities perspective. We have identified that objects potentially defined as boundary objects serve the adaptation process run by the managers for the "sensing", "seizing" and "reconfiguring" phases identified by Teece $(2007,2014)$. We refer to perspectives introduced with the micro-foundations approach (Felin et al., 2012; Felin and Foss, 2011; Barney and Felin, 2013; Foss, 2011) in order to analyze the co-evolution between individuals (and their cognitive apparati), processes, and structures. We expect to investigate here the interactions between the collective and individual managerial practices in addition to processes and structures.

We offer a comparison between two case studies of military jets programs run by Dassault Aviation: Mirage IVA (in the 1950s and 1960s) and Rafale (from the 1980s onwards).

Our contribution sequentially introduces sections dedicated to the theoretical framework, to the description of our research protocol, to the comparative presentation of our case studies and to data analysis, and to the discussion of data against the concepts introduced with the literature review. We conclude with limitations and perspectives for further research.

\section{Theoretical Framework}

This contribution complements the analysis of the orchestration of resources (Teece, 2007, 2014: "sensing", "seizing" and "reconfiguring") with the analysis of boundary objects (Star and Griesemer, 1989; Fong et al, 2007a, 2007b). The last subsection introduces our propositions.

\section{Heterogeneity of Managerial Capabilities and RESOURCES ORCHESTRATION}

The nature of interactions between managers is an essential aspect allowing for the understanding of actual practices (Dougherty, 2001; Felin et al., 2012). Teece (2007; 2014) and Kor et al. (2013) point out that dynamic capabilities in large firms depend on the complex dynamics of vertical vs. horizontal interactions: the orchestration of resources requires organizational flexibility; it is based on managerial interactions at different hierarchical levels. Kor et al. (2013) mention the 'dynamic properties' of managerial capabilities and focus on the top managers' absorption capability. Teece (2014) explains that large firms are specific inasmuch as coordination is less of a vertical and of a hierarchical nature: top and middle managers interact together as in a network, with large areas of informality.

The management of coordination is difficult to understand because it implies cognitive dimensions (Tsoukas and Vladimirou, 2001). Helfat and Peteraf (2015) refer to the concept of managerial cognitive capabilities as an enabler for managers to perform "mental activities" and accept that such a definition directs attention to the content of "cognition". They acknowledge that cognition itself relates to a series of different albeit close definitions. They stress a reference to two components: mental models (or structures, or representations), and mental activities (or processes, or operations). At the individual level, data, information and knowledge feed the cognitive process (Boisot and Canals, 2004). Individual cognition grows from conjectures and refutations (Popper, 1972; Radnitzky and Bartley, 1987; Boisot, 1998). The difficulty at transitioning from individual to team levels materializes with difficulties for managers to locate distributed knowledge among the organization, and to coordinate activities. Helfat \& Peteraf (2015) point out that managerial cognitive capabilities remain heterogeneous as regards "sensing", "seizing" and "reconfiguring". Their research illustrates how management science scholars back up their explanations at team or organization levels with implicit generalizations borrowing from cognitive theories conceptualized at the individual level. When Zollo and Winter (2002) explain that capabilities develop in part through practice, especially in their early stages of development, they open the way towards an understanding of this link: capabilities emerge from individual vs. collective action, that itself follows the cognitive mechanisms respectively applicable to individuals, teams and organization. The difference between individual cognitive processes is amplified by organizational tensions (Tsoukas and Vladimirou, 2001). The juxtaposition of coexisting opposites intensifies tensions, challenges the actors' cognitive limits, demands some creative sense making, and seeks for more fluid, reflexive and sustainable management strategies (Smith and Lewis, 2011).

From a theoretical perspective, a difficulty emerges. The theory of cognition (incl. cognitive psychology) currently provides with several competing explanations of mechanisms framing decision making and capability building at the individual level, but the issue at stake with managerial capabilities and the orchestration of resources is not an individual process. It therefore requires an explicit analysis of the interaction(s) between the individual and collective (team, organization) levels. The rest of this section will focus on this interaction.

\section{Sensing: Individual and Collective Perception and Attention}

"Sensing" is generally considered as an individual cognitive process. The identification of market opportunities situates in a dynamics where "entrepreneurs/ managers have to make informed conjectures about the path ahead" (Teece, 2007: 1323) 
in a context of uncertainty. Going into the micro-foundations of the process, Teece identifies that the creation and/or discovery of opportunities require(s) "both access to information and the ability to recognize, sense, and shape developments" (ibid). He infers the description of the "sensing/shaping" skill from Kirzner's description (1979) of the entrepreneur's "alertness" to make sense of market "noises" (sic).

In essence, such explanations of "sensing" drive back to individual mechanisms and the foundations of (individual) knowledge. Consistently with Teece $(2007,2014)$, Helfat and Peteraf (2015) assimilate the "sensing" with the cognitive processes of perception and attention. They stress that perception involves a range of mental functions, including those related to pattern recognition and to data interpretation. Boisot (e.g. Boisot and Canals, 2004) provided a consistent model explaining how agents make sense of stimuli available in the external world in reference to their existing perceptual and conceptual filters; such filters depend on values, references and mental models. The effectiveness of individual attention mentioned by Helfat and Peteraf (2015) is a direct result of the co-evolution between the individual's perceptual and cognitive filters (in Boisot's words) and the external business environment, which explains its performance in (effectiveness at) "sensing".

The micro-foundations of attention also represent an aspect of such evolutionary process. Attention has been actually defined by Campbell (1974) as an instance of selective process. At an individual level, the effort (cognitive workload) required for making sense of the stimuli of the external world and of the data generated by the perceptual filters directly depends on the correspondence between our existing knowledge and the "noises" (Kirzner, 1979) available in the environment (the organization, the market, etc). Attentional resources are not evenly distributed across individuals: the attentional selective process requires less energy when available resources are effective at making sense of stimuli; when they are not, individuals must invest in improvements of the (perceptual and conceptual) filters and of their knowledge base (in Boisot's words). As Teece (2007) puts it, management must carefully allocate resources to search and discovery because attention (or "alertness") is a scarce resource inside a firm. From an organizational or managerial perspective, we can point out two direct consequences. Individual cognitive processes are a source of diversity and heterogeneity, and specific coordination efforts are therefore a necessity. The scarcity of attention resources shows that collective "sensing" directly depends on specific individual resources.

When looking up beyond the individual level, we need to connect the micro-foundations with collective action (Marrone, 2010; Felin and Foss, 2011). This is one of the missing links in Helfat and Peteraf (2015), because they account for the managers' cognitive capabilities in placing them in isolation and not in interaction. The interactionist perspective has been now developed by scholars working on team effectiveness (Salas, Goodwin and Burke, 2009) and team cognition (Salas and Fiore, 2004). Teamwork involves coordination strategies through close-loop coordination and a sense of collective orientation among groups. Team cognition impacts team performance. A collective workload with communication overheads may attenuate team cognition, while team experience preparing to task dependencies and team coordination improves both team cognition and team effectiveness. Salas et al. (2009) explain that congruence in perception and attention conditions the effectiveness of responses managed at team level, but the emergence of such congruence is not documented beyond the reference to accumulated shared experience and training. Salas, Fiore and their co-authors do not focus on the management of managerial capabilities (as Teece frames it for the orchestration of resources), but they all focus on decision making in safety- and time-sensitive environments. They analyze the elaboration of team level competences and explain that the transition to a team-based appreciation of "sensing" requires a "collective orientation” (Salas \& Fiore, 2004: 4).

\section{Seizing: Individual vs. Collective Problem-Solving and Decision-Making}

Teece (2007) explains the "seizing" of opportunities as making decisions about investments, and transforming opportunities into value. Helfat and Peteraf (2015) for instance illustrate "seizing" with investment decisions or the design of business models. "Seizing" opportunities materializes with individual activities. It is supposed to translate afterwards into organizational capabilities without direct explanation, except the mention that such a black box is handled by psychologists. The main analytical difficulty relates to the introduction of explanations consistently bridging the individual and organizational levels in management science. The contrast between Helfat and Peteraf (2015) and Felin et al. (2012) perfectly instantiates the ambiguity at addressing such an issue. The reference to the word "cognition" hides in reality that these scholars enact discrepant analytical strategies and do not rely on the same "model of mind and man" (Felin and Foss, 2011). They also use implicit propositions on reductionism in social sciences (Petroni, 1991). The discussions of "cognitive styles" in Stanovich (2009) and of the content of decisions in Helfat and Peteraf (2015) need psychology as a back-up because they focus in reality on the contents of decision (ratio essendi). Most authors commenting on "seizing" draw a logical link between individual reasoning and problem solving (e.g. Stanovich, 2009: 28-40). These concepts are closely related. They do not require much of a differentiation as long as the notion of rationality implicitly present in these words associates with a theory of the people (ratio cognoscendi), not of the contents of individual statements (ratio essendi) (Radnitzky and Bartley, 1987: 329; Felin and Foss, 2011). Our contribution focuses on ratio cognoscendi in order to contribute to the theory of the orchestration of resources.

Three aspects make a theoretical difference when analyzing the "seizing" from a ratio cognoscendi perspective. First, from a theoretical perspective, decision-making is a process, not an event (Boland, 2003). Problem-solving results from the actual co-evolution between individual learning process and decision-making capabilities (Campbell, 1974). Second, the outcome of "seizing" eventually relates (among others) to individual rationality when dealing with contents; the process of decision-making conversely depends on managerial and organizational aspects. The concept of "seizing" gets its full explanatory power when introducing rationales about the individual growth of knowledge (as in Felin et al., 2012), here the manager's. Third, decision processes can only logically occur in relation with individuals, but individuals do not make decisions "in a vacuum" (ibid). The first part of the sentence explains why the individual component cannot be avoided, as in the 
micro-foundations approach. The second part of the sentence refers to the ecosystem (Lorenz, 1973; Campbell, 1974) where individuals make decisions: the growth of knowledge depends on the "logic of the situation" (Boland 2003, in Agassi's words). This interdependence between individuals and their ecosystem represents the root cause of routines and capabilities (Felin and Foss, 2011). The growth of knowledge first and foremost applies at individual level yet it situates inside group- or organization-based perspectives. In Felin et al (2012: 1353)'s words: "social processes and structures". These aspects are consistent with some aspects of Tsoukas and Vladimirou (2001) analysis of the articulation between organizational and individual knowledge, even though their reference to Wittgenstein introduces other analytical debates diverting from our research question.

The interaction effect within/ across components specific to an organization can transform individual knowledge into organizational assets. Individuals, processes and structures represent "three building blocks" (Felin et al, 2012) "embedded in a nested and temporal (and even causal) hierarchy". This is the reason why the "seizing" is "enmeshed in different interactions" where making an explicit difference between causes and consequences remains a part of the research agenda.

In this project, the concept of "seizing" is operationalized as a part of an organization-based learning process featuring the co-evolution of individuals, processes, and structures.

\section{Reconfiguring: Communicate and Manage the Organizational Resistance to Change}

The "reconfiguration" step relates to the maintenance of the organization's "evolutionary fitness" and also incurs the ability to "try and escape from unfavorable path dependencies" (Teece, 2007: 1335). Helfat and Peteraf (2015: 24) point out that the "reconfiguring" focuses on phenomena occurring at the organizational level; Teece (2014) refers to "organizational transformation". The orchestration of assets refers to the selection, configuration, alignment, and modification of tangible and intangible assets (Helfat et al., 2007). Adaptation to change in the external environment often requires the enhancement or alteration of strategic assets through innovation and organizational learning (Zollo and Winter, 2002), as well as the acquisition of new assets (Capron and Mitchell, 2009). Even if "reconfiguration" manifests in individual decisions, it represents a collective concept in its very nature. It materializes with the orchestration of assets, the redesign of routines, the realignment of assets, the adaptation or redesign of business models, the redeployment of capabilities in different locations, the minimization of internal conflicts, and the maximization of complementarities and of productive exchanges. Sustaining dynamic capabilities also relates to leadership skills.

Teece (2007) explains that managers in charge of local activities can face cognitive limits if they become prisoners of information filters, of decision making patterns and of local paradigms framing the appraisal of the environment. All managers have to behave as leaders who overcome inertia and resistances to change. The complexity of the "rules of the game" installed with the other actors of the ecosystem (clients and/or competitors) can also shape their vision. The "reconfiguring" associates with cognitive capabilities. As already mentioned for the "seizing", it is possible to dive into different options and eventually refer to psychologistic perspectives (as in Helfat and Peteraf, 2015) or evolutionary epistemology (Renzi et al, 2011), team effectiveness (Salas, Goodwin and Burke, 2009) or team cognition (Salas and Fiore, 2004). These theoretical references do not improve much the understanding of the actual orchestration of resources. For the purpose of this research, it is enough to mention that the "reconfiguring" requires "social skills", supported by "social cognitive capabilities". This relates to individual skills, such as the verbal and non-verbal communication actions for top managers to drive adaptation and growth. Helfat and Peteraf (2015) refer to "social cognition". They use this wording to refer to the installation of cooperative activities across the organization that have been already described by Teece and Pisano (1994): understand the point of view of others, and therefore influence their behaviors; install and foster trust; manage power relations; and overcome barriers to change.

\section{Boundary ObJects and Coordination of Heterogeneous Cognitive Capabilities}

This sub-section bridges the orchestration of resources with the role of boundary objects.

\section{Boundary Objects as (Epistemic) Interfaces between Different Worlds}

Boundary objects (Star and Griesemer, 1989) are usually defined as artifacts that a community or a person works with (Carlile, 2002). They play a pivotal role in coordination in general. Bechky (2003) explains that boundary objects serve transfer and coordination between different worlds and can be used in any managerial activity, not only the ones occurring in the domain of conception and R\&D. Fong et al (2007a) have identified several interface modalities in the boundary object literature: all instantiate different ways to install infrastructures and processes where knowledge can be represented, learned and transformed (Carlile, 2002). Boundary objects take the form of diagrams, maps, sketches, drawings, prototypes, etc. They make it possible to handle the situated and "purposive" (sic) nature of knowledge (in Carlile's words). Objects become "boundary objects" when they are effectively used in order to deal with data, information, knowledge, and related contexts.

"Boundary objects" operate at a minimum of two levels (Wilson and Herndl, 2007): they are open and flexible as global structures that provide meaning for a wide range of actors; they specifically adapt to concrete contexts. The original version of the concept not only acknowledged the incommensurability in communication yet also focused on coordinating activities The concept of boundary object explained how groups holding "irreconcilable epistemologies" could cooperate in spite of hard epistemic oppositions (Wilson and Herndl, 2007). Boundary objects are both understood as "bridge models" (Star, 2010) and "mental models" (Brown and Duguid, 1998). They have to demonstrate a tangible concrete character (Levina and Vaast, 2005; Bechky, 2003) with both respects, and grant easy access and easy appropriation (Lee, 2005). They therefore align with the conclusions identified by Tsoukas (1996) when characterizing a "distributed knowledge system", and most notably his point about tensions, that are only closed "through practitioners exercising their judgment". 
From these aspects, boundary objects may serve the orchestration of resources. In cases where people have to make sense individually of their own data, information and knowledge, and interact with others on these aspects, the properties of the bridge and mental models facilitate interactions. The integration of bodies of literature on boundary objects and on the orchestration of resources seems feasible because the concepts ultimately relate to knowledge-based mechanisms and to the analysis of interactions. It is therefore possible to assume that the use of boundary objects will impact all aspects of the orchestration of resources. Due to the nature of cognitive processes described above, the use of boundary objects will materialize in the individual perception, in the subsequent individual and collective sensemaking mechanisms, and in (collective) decision making processes. The academic literature often investigates the epistemic properties of boundary objects. Authors sometimes dissolve the "mental" issues as properties of the "bridge". This is for instance the perspective adopted by Carlile (2002) who borrows from linguistics and the functions of language. He draws a debatable correspondence between these functions and "types" of boundary objects (2002, Table 2). In spite of the wording and of the apparent managerial content, issues addressed by Carlile (2002) do not relate to the orchestration of resources. Other attributes are required to explore individuals, processes, and structures.

Bechky (2003) and Star (2010) explain how important it is for boundary objects to not have an abstract nature, and to allow for a joint or collective easy execution. The academic literature (e.g. Sapsed and Salter, 2004) has explained the tradeoff between the meaningfulness of boundary objects, and their transferability. In some cases, boundary objects congeal roles and practices and lose all flexibility. These aspects are relevant for the orchestration of resources.

The literature has now converged on several properties: boundary objects represent a facilitation tool serving the transmission and the appropriation of concepts and novel ideas beyond the individuals who initiated them. They mediate the articulation between different worlds and serve the standardization of perspectives. Coordination may occur inside or between communities. Boundary objects bridge negotiations on practices, identities and significations (Wenger et al, 2002; Brown and Duguid, 2001). Boundary objects may locate at the periphery of the communities and still contribute to the creation of new knowledge (Star, 2010; Carlile, 2002). They provide: a framework for the implementation of any activity; a tool for avoiding information asymmetries; trusted and secured exchanges within the platform; considerations about identity, with the creation of a sense of belonging to a collective; easier access to cumulative information and data; and available resources for further computation. These aspects potentially impact the actual ways of working on the orchestration of resources.

Exchanges around boundary objects address issues related to the difference between mutual and common understanding: in "mutual" understanding (Espinosa et al., 2004), individuals understand each other; in "common" understanding (Mohammed et al., 2001), they share the end-result of an epistemic process. Both "mutual" and "common understanding" contribute to deepen the sense of identity and explain the development of trust around the boundary objects. Technology can facilitate the awareness of members with the boundary object, and support apperception (that is the moment where individuals and teams become cognizant of the perception of a problem, the "Ah Ah moment", in Lorenz's words) (Fiore and Schooler, 2004; 136; Salas and Fiore, 2004). The boundary object provides a space similar to the "problem space" identified as an enabler to conceptualization in cognitive sciences, which seems similar to the sequence between "sensing" and "seizing" in the orchestration of resources. The analysis follows the existence of positive transaction costs in relation with cognitive aspects, and with knowledge creation; it draws links between the "value" of created knowledge, the "value" of appropriated knowledge, and the management of resources during the interaction (Foss and Foss, 2005). Boundary objects seem to support apperception, and generate its related "space". Using the words introduced by Foss and Foss (2005) would lead to consider boundary objects as instances of a transaction costs-reducing "technology", also lowering knowledge "value" dissipation and erosion.

\section{Functionalities of Boundary Objects in Managerial Context}

Definitions and investigations usually focus on the nature of boundary objects and do not attempt at exploring their actual use for managerial tasks. Star and Griesemer (1989) and Star (2010) have identified properties in relation with functionality, utility, granularity, familiarity and synchronization. In order to appraise the microfoundations of the boundary objects' managerial impact on the orchestration of resources, we need to go deeper into the details of the properties already discussed by Fong et al. (2007a, 2007b) in a different context.

Star points out that the types of boundary objects directly incur a series of consequences. Types translate into the physical content of the boundary object, for instance as a document repository supporting information processes, or as an ideal type operating either as a bridge model (sharing issues in crossing tacit knowledge and semantic information on discrepant fields of activities) or as a mental model (a support for the reconstruction of a common cognitive tool, dedicated for instance to problem resolution).

The level of granularity explores two different yet complementary aspects: the volume of information and data available, and the options for disambiguation. It is sometimes necessary to increase the detailed description of the boundary object in order to be able to grasp the problem to be solved, or to enable interactions (understanding) between users of the boundary object. Increased granularity allows for more precise interactions, and for handling more complex knowledge processes. An increased granularity is not automatically possible as the technology underlying the boundary object may introduce (feasibility-related) limitations.

The malleability of the boundary object describes its capacity to accommodating problems and issues that it was not intended for. Fong et al (2007b) point out the ability at handling new layers of data, and at potentially solving new problems with the support of the boundary object. Some authors (e.g. Fong et al, 2007a) refer also sometimes to the malleability in order to cover aspects associated to the boundary object's "openness", and use both words in interchangeable ways. It seems much more adequate to refer to the property of openness for the characterization of communication and collaboration issues, 
for instance entry costs and new users. Malleability refers to technical contents of the boundary object while the openness deals with the interaction between the boundary object and its users. The degree of openness varies with respect to the observability of processes underlying the information contained in the technology of the boundary object (Swarts, 2004). Digital types have for instance more malleability and more openness than physical types.

Both granularity and openness depend on the completeness that refers to an eventual exhaustive description of the problem, and to the ability to appraise the question. This attribute is driven by the number of available "layers" (Swarts, 2004) inside the boundary object, and by the technology potentially accepting an improved granularity (i.e. new details inside a layer). The materialization of completeness illustrates for instance with the ability to make sense of tacit knowledge during interactions with other users of the same boundary object.

Our research question focuses on the contents of interactions between individuals, teams and organizations contributing to the "sensing", "seizing" and "reconfiguring" steps. The different properties of a boundary object will contribute to understanding the reduction of the heterogeneity of cognitive capabilities among the users of a boundary object. Its effectiveness will show through interactions.

\section{Bridging Together the Orchestration of RESOURCES AND BOUNDARY OBJECTS}

In this contribution, we introduce several proposals on boundary objects and how they contribute to the orchestration of resources. We recapitulate on the different aspects of our literature review with the figure below. Teece (2014) introduces several perspectives about strong dynamic capabilities (2014) that request the ability to handle signature processes and achieve superior coordination. We intend to show how the properties of boundary objects may help to better understand the management of coordination, and the heterogeneity of cognitive capabilities in the orchestration of resources. Teece (20014) and the scholars working on dynamic capabilities have always stressed the need for agility and the need for signature processes in order to be able to handle capabilities difficult to replicate. We propose boundary objects as an instance of "technology" suited to generating strong organizational agility, the associated framework and "space" where interactions take place, and the subsequent routines.

We introduce five propositions bridging the properties of boundary objects with the orchestration of resources. The table below also documents our propositions further.

1. Boundary objects generate a cognitive space suited to the orchestration of resources; the subsequent "bridge model" primarily supports the "sensing" and "seizing" phases.

2. Boundary objects provide a cumulative access to data, information and knowledge empowering a team (cf. mutual and common understanding), in particular in the "seizing".

3. Boundary objects create convergence between the stakeholders using them ("seizing").

4. The boundary object's cognitive space and the subsequent mutual understanding lower the resistance to change (with an impact on the "reconfiguration" phase), which requires specific managerial actions (and leadership).

5. Reduced transaction costs induced by the boundary objects support the management of complexity, and affect all aspects of the orchestration of resources.

\section{Method and Research Design}

We offer a comparative, exploratory and theory-building case study (Yin, 2009). We adopt an abductive methodology aligned with the precepts of grounded theory (Glaser and Strauss, 1967) and, more precisely with Strauss and Corbin's interpretation of the theory (1990). As an inferential strategy defined as the retrospective process of forming hypotheses (Fylkelnes, 2006), abduction is well suited to dealing with incomplete evidence under conditions of complexity, and to generating "tentative theories" that suggest hypotheses (Niiniluoto, 1999, 2007; Thomas, 2010). Our research is "conceptually driven" (Miles and Huberman, 1994: $238 \mathrm{n} 2$ ). In this section, we introduce a description of fieldwork, including data collection and data reduction. The abductive process materializes with more precise propositions and further steps of data collection, thus generating greater levels of "explicitness" and "groundness".

\section{FIGURE 1}

Proposed model for the articulation of boundary objects and the orchestration of resources

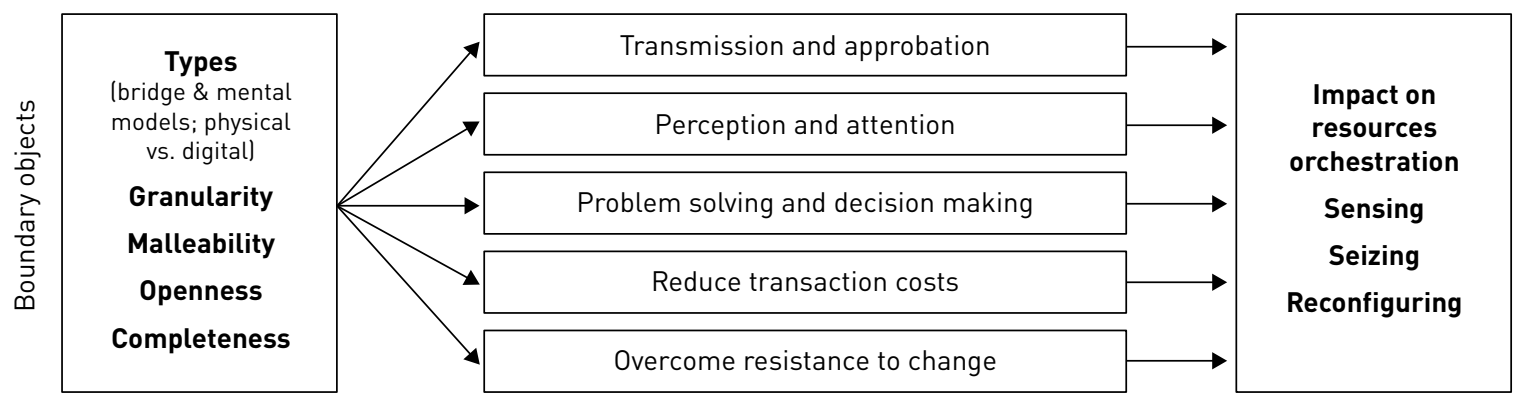

Microfoundation (individuals, processes and structures) 


\begin{tabular}{|c|c|c|c|}
\hline \multicolumn{4}{|c|}{$\begin{array}{c}\text { TABLE } 1 \\
\text { Synthesis of propositions on Boundary objects and Dynamic capabitities }\end{array}$} \\
\hline $\begin{array}{l}\text { Dynamic } \\
\text { (managerial) capabilities }\end{array}$ & Sensing & Seizing & Reconfiguring \\
\hline $\begin{array}{l}\text { Subsequent } \\
\text { cognitive capabilities }\end{array}$ & $\begin{array}{l}\text { - Perception } \\
\text { - Attention }\end{array}$ & $\begin{array}{l}\text { - Problem-solving } \\
\text { - Decision-making } \\
\text { - (Reasoning) }\end{array}$ & $\begin{array}{l}\text { - Communication } \\
\text { - Overcome resistance } \\
\text { to change }\end{array}$ \\
\hline $\begin{array}{l}\text { Heterogeneity of } \\
\text { cognitive capabilities }\end{array}$ & $\begin{array}{l}\text { Generate congruence } \\
\text { in cognition }\end{array}$ & Install joint learning processes (co-evolution) & $\begin{array}{l}\text { Installation of cooperative } \\
\text { activities }\end{array}$ \\
\hline \multirow{4}{*}{$\begin{array}{l}\text { Propositions } \\
\text { on boundary objects (BO) }\end{array}$} & \multirow{3}{*}{$\begin{array}{l}\text { P\#1 B0 generate } \\
\text { the cognitive space } \\
\text { (bridge model) } \\
\text { required for "Sensing" }\end{array}$} & P\#1 The B0's bridge model facilitates the "Seizing" & \multirow{3}{*}{$\begin{array}{l}\text { P\#4 Interactions } \\
\text { around the BO support } \\
\text { the change process in } \\
\text { improving acceptability } \\
\text { and alignment, and lower } \\
\text { resistance to change }\end{array}$} \\
\hline & & $\begin{array}{l}\text { P\#2 The B0 provides cumulative access to D-I-K } \\
\text { empowering a team for the "Seizing" }\end{array}$ & \\
\hline & & $\begin{array}{l}\text { P\#3 B0s create convergence for team-based } \\
\text { "Seizing" }\end{array}$ & \\
\hline & \multicolumn{3}{|c|}{ P\#5 Reduced transaction costs improve the management of complexity } \\
\hline
\end{tabular}

Source: Adapted from Helfat and Peteraf, 2015

\section{Data Collection}

The exploratory case study offered in this project analyzes two fighter aircraft programs commissioned by the French Defense (Mirage IV, Rafale) to Dassault Aviation. Field research covers more than 50 years of technological evolution in military aviation. Complements on related (military) aircraft programs have been also introduced as required (for instance the Mirage 2000). For the sake of comparability, fieldwork has been limited to the three technical domains of aircraft design, avionics, and telecoms.

This research develops from more than 50 (unstructured or semi-structured) interviews held in the aerospace industry, in the French administration and in the French Air Force:

- conception and aircraft design engineers (in charge of the whole programs or subsystems);

- engineers and test pilots for each program;

- executives in charge of acquisition and of program management ( $R \& D$, retrofit) for the administration (namely DGA, a part of the French Ministry of Defense);

- maintenance engineers for the programs or for subsystems; and,

- users (pilots, flight officers, engineer officers, squadron leaders and mission commanders).

Interviews all lasted a minimum of 90 minutes per interviewee, held between 2000 and 2013. Returns on experience, appraisal of concepts, cross-appraisal of technological innovation, and analysis of governance patterns were addressed during the interviews. Interview guidelines focused on competences, the organization of activities (incl. tests and essays), and rationales for the management of technology or decision making in the programs. We also asked the interviewees to describe the elaboration of specifications and activities with actual stories. Field research developed in two parallel and disconnected streams, one per program. The research protocol did not focus at first on boundary objects, but on the orchestration of resources for the management of innovation and on the industrial organization. Boundary objects emerged as dominant patterns in each program, and therefore justified a new focus.
The research protocol faces specificities. We compare two programs with very different timelines. Data collected differ in their nature. Direct observation "on the field" remained impossible in both cases, and would have not brought any useful insight due to the technical contents of interactions. Databases and archives (pictures, reports, recordings) stored by the history departments of the French Air Force and of the French Defense procurement agency (DGA) were used in this research, as well as the ones available from associations of civilian engineers in the industry. Decision makers and test pilots active in the Mirage IV were still alive in the early 2000s when this research was initiated. We mirrored the investigation for the Rafale program in a second phase.

Former French Air Force senior officers themselves, with a mission on exploring industrial organization, organizational designs, and R\&D policies for more than 10 years, the authors were granted unlimited access to information on the programs, clearances and the required cultural background. This is the reason why the authors had the opportunity to identify, and then work with, "informants" with high technological profiles: former test pilots with positions in the administration (DGA) or the industry (Dassault Aviation), and former programs directors representing the French MoD or the French Air Force. Trusted interactions made it possible to challenge all data analysis with them, and confront perspectives. Most technologies covered in this research relate now to data and information publicly available in specialized journals and the professional press.

\section{BACKground Information About Dassault Aviation Mirage IV and Rafale}

The programs developed in different political, strategic, and budgetary contexts.

Dassault Mirage IV program translates the French political will of installing an independent nuclear deterrence force in the 1950s. The program has been managed under heavy time constraints and without major budgetary restrictions. Mirage IV was launched in November 1956; the first "serial" aircraft was delivered and "combat certified" in 1964. The last 
aircraft was decommissioned in June 2005. The Mirage IV program materializes radical innovations for aviation in general, and for fighter aircraft in particular: it has been designed to fly higher, faster and for longer missions (time and distance) than any other aircraft of its time.

Dassault Rafale instantiates at the same time four major evolutions: the insertion of the aircraft in network centric warfare; the evolution of missions and operations incurred by the end of the Cold War; a total polyvalence; and the impact of budgets reductions on Defense. The program belongs to the "4+" generation for fighter aircraft. It was launched in 1982. The first aircraft was delivered at F1 standard in 1998 and "combat certified" in 2002. Several countries operate the aircraft in the world, most notably the French, Egyptian and Indian Air Forces.

Mirage IV and Rafale differ with respect to the nature of complexity. Mirage IV is "simple" because it focuses on a single mission: high and low altitude strategic (nuclear) bombing. Rafale materializes the concept of multi-roles polyvalence designed by Dassault Aviation (e.g. air-to-air combat, air-ground bombing and reconnaissance during the same flight). Full multi-roles polyvalence makes the Rafale a very complex program. Mirage IV follows the modular type (cellule, navigation, bombing system, jet engines, etc.) (Henderson and Clarck, 1990) while Rafale is a case of integral architecture (systems and calculators for the piloting of an "unstable" aircraft and for real time data fusion with command and control networks).

The institutional framework ruling upon each program has remained stable over time, in spite of a series of reforms and reorganizations in the French Ministry of Defense and in the French Defense procurement agency (DGA) (Mérindol and Versailles, 2010).

Industrial activities relevant for this research link today to two companies: Dassault and Thales. The industry benefits from a great stability in spite of new names, new perimeters, fusions and acquisitions. Similar domains of competences prevail in both programs (with the obvious impacts of R\&D and technology evolution). The same repartition of responsibilities exists in the industrial integration chain: Dassault Aviation acts as lead system integrator in both cases. It has now strengthened its links with Thales with a reference stake in its capital structure. A major evolution occurred in the 1980s: tools and methods for 3-dimensional computer-aided design software (CAD) emerged with the Dassault Systèmes (3DS) company. In 1981, 3DS took its autonomy from Dassault Aviation (conception, fabrication, etc.) in Dassault Group.

The institutional and industrial ecosystem is driven by long-lasting relations between the same organizations; it is populated with several interconnected generations of engineers and scientists. Boundaries between competence domains stabilize over time because public policies promoted this strategy with mergers and acquisitions. Individuals and organizations already present in the ecosystem obviously hold an "insider" advantage because they know how to propose cost-effective solutions, how to drive projects while articulating with long lasting aeronautic programs, and how to integrate all these solutions together. The threat of new entrants does however exist because of the demand for constant innovation. The orchestration of resources is no rhetorical question for the aerospace industry.

\section{DATA REDUCTION}

We compared the uses of the boundary objects in both programs. We could appraise roles and activities with the boundary objects, and the co-evolution between individuals, processes, and structures (micro-foundations approach). The boundary objects were confronted to the processes of data and information sharing, and of knowledge elaboration in "sensing", "seizing" and "reconfiguring".

The analysis has been carried out with a coding procedure of interview transcripts. Most interviewees told stories and anecdotes on actual activities around the development of the respective boundary objects, and their uses inside the respective programs. We created the initial list of codes on the basis of the literature review. In line with the abductive approach, codes were added, changed and adjusted during the data reduction and data display phases. Once coded, information was brought together for each project with a working memo. A second step has been then carried out in confronting the boundary objects against each other in order to identify common patterns and singularities and to translate the data into the metrics described in table 2 below. These aspects were discussed with our "informants" in order to situate the analysis of interactions inside a greater perspective linked to the evolution of technologies, and of military aviation. This repetitive process illuminated data display, thus clarifying the initial proposition(s) and generating theory. Our comparison supports the appraisal of causality links between the identified variables (Eisenhardt, 1989), which makes the comparative case study significant (internal validity). Codes documented in the tables below were also tested with our "informants".

\section{Data Display; Data Analysis}

The section first displays the properties of the boundary objects (type, granularity, openness, malleability, and completeness), and then analyzes the orchestration of resources.

\section{Properties of Boundary Objects in the Mirage IV and Rafale Programs}

\section{Roles of the Boundary Objects in the Mirage IV A and Rafale Programs}

The main important issues to be solved on Mirage IV link with the complexity of running multiple communication systems in parallel at the same time. Compatibility and interference issues were discovered when engineers and scientists confronted to the irrelevance of their successive designs. Dassault Aviation and the DGA's test and essays office consequently gathered specialists and experts in charge of each communication, command and control sub-system and avionics. They facilitated the design of a scale-1 model in order to generate a comprehensive picture of the problem, and installed a trial and essay process that led progressively to the relevant solution. The prototype was built at the test and essays facilities in Istres air force base. The program director for DGA extensively describes how electric, electronic, and electromagnetic devices were installed on the prototype in order to gather data showing the performance levels with or without integration of the other components. Eventual electro-magnetic interferences were tested for all positions of antennas, sensors, cables and devices (including turning the model up-side-down in order to test the air-ground 


\begin{tabular}{|c|c|}
\hline & $\begin{array}{l}\text { TABLE } 2 \\
\text { Metrics for the data reduction process }\end{array}$ \\
\hline Boundary object & Metrics used for data reduction \\
\hline \multirow[t]{3}{*}{ Type } & $\begin{array}{l}2 \text { boundary objects types: physical (tangible objects) vs. virtual (or digital) (bytes and bits, stored in computers } \\
\text { and databases) }\end{array}$ \\
\hline & Context: Bridge model vs. Mental model \\
\hline & $\begin{array}{l}\text { Cognitive usefulness, i.e. the relevance for the BO users: Pseudo-quantitative assessments, from "no utility", } \\
\text { to "weak" or "low", "medium" and "high" }\end{array}$ \\
\hline Granularity & $\begin{array}{l}2 \text { directions: the volume of information and data available, and the options for disambiguation. Assessments for } \\
\text { both directions go with pseudo-quantitative scales, from "void" to "high". }\end{array}$ \\
\hline Malleability & $\begin{array}{l}\text { The BO's ability at accommodating issues and problems that it was not intended for: this eventually requires a } \\
\text { pseudo-quantitative scale from "void" and "low" to "high". It concretizes also with the ability at introducing new } \\
\text { layers of data if required. }\end{array}$ \\
\hline \multirow[t]{2}{*}{ Openness } & $\begin{array}{l}\text { The metrics account for the capacity at handling new communication and collaboration issues with the other BO } \\
\text { users, and therefore goes with pseudo-quantitative from "void" and "weak" to "high". }\end{array}$ \\
\hline & $\begin{array}{l}\text { The cost of entry into the BO from the perspective of adapting to new BO users: pseudo quantitative from "void" } \\
\text { to "weak" and "high". }\end{array}$ \\
\hline \multirow[t]{2}{*}{ Completeness } & $\begin{array}{l}\text { The metrics relates to the volume of available data, or to the ability of sharing tacit knowledge and reaching } \\
\text { "mutual" vs. "common" understanding with the other BO users. }\end{array}$ \\
\hline & To be also assessed: the cost of entry into the BO from the perspective of completeness only. \\
\hline
\end{tabular}

radar in realistic conditions). Contributors to tests and essays jointly analyzed all interferences and adjusted the repartition of subsystems on the scale-1 model. They modified and/or optimized the specifications of each sub-system and handled compatibility issues. Most activities focused on the sensing and seizing phases: discovering interferences, analyzing the unexpected phenomena, providing tentative solutions, and testing them before making final decisions. The reconfiguring domain materialized with the identification of relevant competences, the design of complementary $R \& D$ activities, and the installation of adapted production systems.

The people in Dassault Aviation ecosystem discovered the relevance of interacting with a boundary object at the time of Mirage IV. They understood its relevance for solving integration issues. These ways of working have thereof become the norm.

Rafale is a fully digital aircraft for avionics, communication and controls, designed with fly-by-wire systems. Software is everywhere. As in many other digital systems for Defense, performance directly depends on digital commands and on software versions. Piloting the aircraft without on-board calculators, and executing missions without data fusion and network centric connectivity, are impossible by design. Most technologies related to avionics and telecoms embody incremental developments. Integrated on this "multi-roles" aircraft, they generate new levels of complexity. The digital 3D model generated with Dassault Systèmes software suites makes it possible to handle such radical challenges. Only engineers and scientists trained and skilled with both the CAD technology and the interaction with the $3 \mathrm{D}$ model can contribute to problem solving. Some activities still relate to position issues for cables, devices, calculators, antennas, etc. In contrast with Mirage IV, the software code and the effectiveness of software programming impact as much the overall performance as the positions of hardware. Aircraft design has to anticipate on retrofit phases where software will be updated without upgrading the hardware. The "sensing" step is still challenging, yet making decisions ("seizing") at system level (i.e. the aircraft), and the "reconfiguring" of local and system-level contributions during the integration process have gained in (relative) importance.

\section{Comparing the Properties of Mirage IV A and Rafale Boundary Objects}

The comparison between Mirage IV and Rafale shows immediately that the impact of the respective boundary objects on coordination, communication and collaboration follows their types, and most specifically their analog vs. digital natures. This distinction impacts the activities related to both aircraft programs through the very same functions of "bridge model", that frame the interaction between worlds embodied in the different actors. The appraisal of the "mental model" follows the dynamics of the learning process with joint problem resolution, and the understanding of gaps.

Openness relates to the entry costs in the boundary object and to the observability of the artifacts. In the Mirage IV case, openness is high and entry costs are low because contributors generated the boundary object during their interactions, and during actual joint test and essay activities: R\&D engineers designed the scale- 1 model and all contributors brought their own hardware to populate the boundary object. Easy re-appropriation of the object itself almost automatically ensued. Experiments decided the debates on the interpretation of data and phenomena, and boundary object's users were able to articulate their knowledge together.

The Rafale digital boundary object was generated with a 3D CAD software: its entry costs are high because they demand abstraction and codification skills (Boisot, 1998). The observability of phenomena and the eventual re-appropriation of the boundary object depend on the ability to interacting with abstract and codified models. 
The malleability issue also represents a corollary of the analog vs. digital nature of the boundary object. The physical boundary object for Mirage IV had a single purpose. Accommodating new problems beyond electro-magnetic issues would have required the elaboration of another (physical) boundary object. The same evolution demands only adjustments and extensions in the digital object used for Rafale. The same holds for granularity, and for the eventual necessity of introducing new levels of details in order to handle further technological details into the existing layers. In the Rafale program and its digital boundary object, adjustments allowing for zooming in and out remain easy to implement - but costly in time and effort.

In the domain of completeness, the volume of data taken into account when working with Mirage IV physical boundary object are obviously limited to its initial purpose, while the volume of data potentially accommodated for the Rafale is unlimited due to the digital nature. The sharing of tacit knowledge is easy on the physical boundary object, and directly follows the trial and error process implemented by the boundary object users. It is not difficult per se with the digital boundary object used for Rafale, yet depends then on the ability at coping with codification and abstraction.

The main difference between these boundary objects always involves to some extent the oppositions between physical vs. digital model and the modular vs. integral architectures.

\section{Contributions of The Boundary ObJects to THE OrCHESTRATION OF RESOURCES}

\section{Contributions of Mirage IV Boundary Object to the Orchestration of Resources}

In Mirage IV, the joint learning process produces at the same time the scale-1 model, the grasping of scientific and technical issues ("sensing"), the (joint) proposition of decisions ("seizing") and the subsequent "reconfiguration" elements: competences, organization of the next R\&D activities, and orientations for the aircraft design (including the organization of the supply chain, of production lines, and of integration activities). The focal point of the Mirage IV case drives most explanations back to the impossibility at handling the "sensing" and "seizing" phases without a boundary object. The context of a modular architecture only plays a direct role insofar as it allows the boundary object to focus on one single purpose.

We can now expand the table comparing the boundary objects in these programs and point out the links between the properties of boundary objects and the orchestration of resources. The boundary object mainly served the exploration of a specific technical problem for Mirage IV, therefore a major focus on the "sensing" phase that frames the analysis of the boundary object's openness, malleability and completeness. The issue with malleability remains inside the scope of the objectives assigned to the boundary object once its applicability perimeter has been

\begin{tabular}{|c|c|c|c|}
\hline BO properties & Detailed description & Mirage IV & Rafale \\
\hline Type & Architecture & Modular architecture & Integral architecture \\
\hline \multirow[t]{2}{*}{ - Bridge model } & Crossing boundaries between worlds & Physical model & 3D digital model \\
\hline & Joint understanding & $\begin{array}{l}\text { Interdisciplinary common } \\
\text { framework }\end{array}$ & Coordination \\
\hline \multirow[t]{2}{*}{ - Mental model } & Joint problem resolution & $\begin{array}{l}\text { Joint learning process on } \\
\text { a physical model }\end{array}$ & $\begin{array}{c}\text { Joint learning process with } \\
\text { a digital model }\end{array}$ \\
\hline & Understanding gaps & Trial and error process & Abstraction, codification \\
\hline \multirow[t]{2}{*}{ Granularity } & Comprehensive and detailed information & $\begin{array}{l}\text { No limit in the technical domains } \\
\text { linked to the physical BO }\end{array}$ & No limit \\
\hline & Options for disambiguation & $\begin{array}{l}\text { Easy addition of details on the } \\
\text { BO domains }\end{array}$ & Easy addition of any additional detail \\
\hline \multirow[t]{4}{*}{ Openness } & Acceptation of new contributors & $\mathrm{HIGH}$ & LOW \\
\hline & Entry costs in the BO (new BO users) & LOW & $\mathrm{HIGH}$ \\
\hline & Observability of processes & $\mathrm{HIGH}$ & UNEASY (codif, abst) \\
\hline & Re-appropriation by BO users & $\mathrm{HIGH}$ and EASY & UNEASY (codif, abst) \\
\hline \multirow[t]{2}{*}{ Malleability } & Handling new technical issues & $\begin{array}{l}\mathrm{HIGH} \text { and EASY in the BO single } \\
\text { purpose }\end{array}$ & $\begin{array}{l}\text { HIGH and EASY with several } \\
\text { BO purposes }\end{array}$ \\
\hline & $\begin{array}{l}\text { Introducing new layers of data } \\
\text { if required }\end{array}$ & LIMITED & UNLIMITED \\
\hline \multirow[t]{3}{*}{ Completeness } & Volume of data accommodated in the BO & LIMITED & UNLIMITED \\
\hline & Ability at sharing tacit knowledge & $\mathrm{HIGH}$ and EASY & UNEASY (codif, abst) \\
\hline & $\begin{array}{l}\text { Reaching common / mutual } \\
\text { understanding }\end{array}$ & $\begin{array}{l}\text { HIGH lactual trial and errors), } \\
\text { COMMON understanding }\end{array}$ & $\begin{array}{l}\text { HIGH MUTUAL understanding with } \\
\text { codif and abstr. skills }\end{array}$ \\
\hline
\end{tabular}


defined. It is different on the necessity of completeness, and in the openness to new users. The retrospective assessments introduced by interviewees show that the "reconfiguring" phase was always easy to handle (R\&D actions, organization of supply chain, and preparation of production). The direct articulation between individuals, processes, and structures around the boundary object made it easy to accept the consequences of the "seizing", and to re-appropriate its consequences in the "reconfiguration" of the program. The other properties, granularity and malleability, did not play a major role.

The joint trial and error process around the boundary objet made it possible to reach an easy common understanding ("individuals understand each other"). Reports by the actors of the process show that they were truly concerned with understanding interferences together. They behaved as scientists in a joint research lab, eager to learn from each other. This is also the reason why the location of the boundary object in a flight test facility has been important. They adhered to the local mindset, with an intense focus on the experimental method. The direct confrontation with experiments made it impossible to hide behind just words. When reality kicked back, the "purposive" nature of knowledge (Carlile's words) mobilized the 'pragmatic' function of the boundary object.

\section{Contributions of Rafale Boundary Object to the Orchestration of Resources}

Local sensing for the Rafale seems simple at component knowledge level (Henderson and Clark, 1990), yet not often effective when integration issues are not (jointly) understood. Only the individuals who developed a comprehensive picture of the Rafale system thanks to the boundary object were able to bring in an accurate "sensing", and an effective "seizing". This follows the architectural nature of knowledge. Users of the boundary object contributed then with "reconfiguration" proposals; the system integrator and the client have the final cast for the organization of contributions in the integration network. The Rafale program instantiates a problem in knowledge articulation: the difficulty relates to the systemic consequences of any decision made in the program due to its integral nature. The "seizing", and the anticipation on consequences for "reconfiguration", gain therefore in relative importance as compared to the Mirage IV program, even though the "sensing" remains complex and challenging. The openness to new contributors and the management of competences directly depend on the relevance of the mental model (perceptive and cognitive filters; knowledge base). There is no big issue with the bridge model anymore, as contributing individuals and organizations are all trained to working with the digital model. Due to the digital nature of the boundary object, all stakeholders have a direct access to its content if the system integrator and the client of the program grant the clearances. The system integrator facilitates the boundary object and owns a comprehensive detailed pictures, most specially on the "seizing" and "reconfiguring".

The properties of the boundary object have now different relative importances in the orchestration of resources. All interviews acknowledge the major importance of the boundary object for the "seizing" and "reconfiguring": it has become almost impossible to make a decision, and to anticipate on systemic consequences of any technological change without its support. The Rafale boundary object illustrates specific characters of the digitalization: issues to be solved cannot relate to any "fixed product" and to "well-bounded questions" (Nambisan et al, 2017). Contributors at component level explain that handling their local duties proves to be easy because they implement ways

\begin{tabular}{|c|c|c|c|c|}
\hline \multicolumn{5}{|c|}{$\begin{array}{l}\text { TABLE } 4 \\
\text { Mirage IV boundary object's contributions to Sensing, Seizing and Reconfiguring }\end{array}$} \\
\hline Boundary object & Concretely in Mirage IV & Sensing & Seizing & Reconfiguring \\
\hline \multirow[t]{2}{*}{ Type } & MODULAR architecture & & & \\
\hline & PHYSICAL boundary object & & & \\
\hline \multirow[t]{2}{*}{ - Bridge model } & Crossing boundaries between worlds & VERY HIGH & VERY HIGH & MEDIUM \\
\hline & Joint (COMMON) understanding & VERY HIGH & $\mathrm{HIGH}$ & MEDIUM \\
\hline \multirow[t]{2}{*}{ - Mental model } & Joint problem resolution & VERY HIGH & VERY HIGH & MEDIUM \\
\hline & Understanding gaps & VERY HIGH & $\mathrm{HIGH}$ & LOW \\
\hline \multirow[t]{2}{*}{ Granularity } & Comprehensive + detailed information & $\mathrm{HIGH}$ & $\mathrm{HIGH}$ & $\mathrm{HIGH}$ \\
\hline & Options for disambiguation & $\mathrm{HIGH}$ & $\mathrm{HIGH}$ & $\mathrm{HIGH}$ \\
\hline \multirow[t]{4}{*}{ Openness } & Acceptation of new contributors & VERY HIGH & $\mathrm{HIGH}$ & LOW \\
\hline & Entry costs in the BO (new BO users) & VERY HIGH & $\mathrm{HIGH}$ & LOW \\
\hline & Observability of processes & $\mathrm{HIGH}$ & $\mathrm{HIGH}$ & LOW \\
\hline & Re-appropriation by BO users & VERY HIGH & VERY HIGH & VERY HIGH \\
\hline \multirow[t]{2}{*}{ Malleability } & Handling new technical issues & LOW & LOW & LOW \\
\hline & Introducing new layers of data & VERY HIGH & VERY HIGH & MEDIUM \\
\hline \multirow[t]{3}{*}{ Completeness } & Volume of data accommodated in BO & VERY HIGH & VERY HIGH & LOW \\
\hline & Ability at sharing tacit knowledge & VERY HIGH & $\mathrm{HIGH}$ & LOW \\
\hline & Reaching COMMON understanding & VERY HIGH & VERY HIGH & LOW \\
\hline
\end{tabular}


of working related to the boundary object. Practical difficulties locate in the ability to accommodating incremental developments and new layers required for the elaboration of new aircraft specifications, or improved perspectives on existing layers of data. The properties of malleability and granularity represent therefore the starting point for making effective decisions. This impacts the communication with other stakeholders in a subsequent round of interactions (starting with the "sensing" again) which here relates to the openness. In the "reconfiguring" phase, the system integrator eventually complements the ecosystem with new competencies, and assigns the respective duties.

\section{Discussion: Limits and Conclusions}

We first point out several limitations to this research.

From a methodological perspective, we have not been able to develop direct observation and check on the self-declarations introduced by interviewees. This represents an important limit in our research, even though working with "informants" and cross validating the interviews from different categories of stakeholders mitigated the risks of mis- or over-interpretation. It would be however necessary to install a new research protocol on contemporary events.

We have also carried out this research in an integration network, where stakeholders build together (and experience on a daily basis) long lasting and stable interactions around a focal actor, which strong hierarchical power over the other contributors to the network. This specific feature impacts several properties, in particular the openness of the boundary object.

With this research, we identify four main results. With the first subsection, we discuss our propositions. The three subsequent subsections open the floor towards further developments.

\section{Boundary Objects Have Diverse Impacts on "Sensing”, "Seizing” and "Reconfiguring"}

Boundary objects do not have the same impact on the "sensing", "seizing" and "reconfiguring".

The model designed for Mirage IV took advantage of congruence in cognition (focus on perception and attention in "sensing") and on a joint learning process (co-evolution of "sensing"). There was no resistance to change, just the necessity of identifying the what and how for "reconfiguring". The Rafale boundary object copes with the complexity of the aircraft and shifts the focus towards "seizing", and the "reconfiguring" at the level of the program ecosystem.

Boundary objects relate to bridge and mental models, and rely on cognitive and perceptual filters enforced in a conjectures and refutations process (Campbell, 1974). Both cases emphasize the relevance of bridging multiple competences and experiences (proposition \#2). Epistemic processes differ but the boundary objects prove their effectiveness.

The cases show also that the properties of boundary objects complement the analysis of types and supply the background for improved propositions on the managerial "purpose" already identified by Carlile (2002). Types and properties illuminate different aspects of how boundary objects reduce the heterogeneity of the managers' cognitive capabilities at team level, and allow for different ways of coordinating, collaborating and communicating. In other words, they impact the management of individuals, processes and structures that are part of the microfoundations approach. The cases support our propositions $\# 1$, \#2, \#3, \#4 and \#5: the cognitive space in both boundary objectspositively impacts the orchestration of resources.

\begin{tabular}{|c|c|c|c|c|}
\hline \multicolumn{5}{|c|}{$\begin{array}{l}\text { TABLE } 5 \\
\text { Rafale boundary object's contributions to Sensing, Seizing and Reconfiguring }\end{array}$} \\
\hline Boundary object & Concretely in Rafale & Sensing & Seizing & Reconfiguring \\
\hline \multirow[t]{2}{*}{ Type } & INTEGRAL architecture & & & \\
\hline & DIGITAL boundary object & & & \\
\hline \multirow[t]{2}{*}{ - Bridge model } & Crossing boundaries between worlds & $\mathrm{HIGH}$ & $\mathrm{HIGH}$ & $\mathrm{HIGH}$ \\
\hline & Joint (MUTUAL) understanding & $\mathrm{HIGH}$ & $\mathrm{HIGH}$ & $\mathrm{HIGH}$ \\
\hline \multirow[t]{2}{*}{ - Mental model } & Joint problem resolution & $\mathrm{HIGH}$ & VERY HIGH & VERY HIGH \\
\hline & Understanding gaps & $\mathrm{HIGH}$ & VERY HIGH & VERY HIGH \\
\hline \multirow[t]{2}{*}{ Granularity } & Comprehensive + detailed information & $\mathrm{HIGH}$ & $\mathrm{HIGH}$ & VERY HIGH \\
\hline & Options for disambiguation & $\mathrm{HIGH}$ & $\mathrm{HIGH}$ & VERY HIGH \\
\hline \multirow[t]{4}{*}{ Openness } & Acceptation of new contributors & MEDIUM & VERY HIGH & $\mathrm{HIGH}$ \\
\hline & Entry costs in the $\mathrm{BO}$ (new $\mathrm{BO}$ users) & MEDIUM & VERY HIGH & $\mathrm{HIGH}$ \\
\hline & Observability of processes & MEDIUM & VERY HIGH & $\mathrm{HIGH}$ \\
\hline & Re-appropriation by $\mathrm{BO}$ users & MEDIUM & VERY HIGH & $\mathrm{HIGH}$ \\
\hline \multirow[t]{2}{*}{ Malleability } & Handling new technical issues & VERY HIGH & VERY HIGH & VERY HIGH \\
\hline & Introducing new layers of data & VERY HIGH & VERY HIGH & VERY HIGH \\
\hline \multirow[t]{3}{*}{ Completeness } & Volume of data accommodated in BO & $\mathrm{HIGH}$ & $\mathrm{HIGH}$ & $\mathrm{HIGH}$ \\
\hline & Ability at sharing tacit knowledge & $\mathrm{HIGH}$ & $\mathrm{HIGH}$ & $\mathrm{HIGH}$ \\
\hline & Reaching MUTUAL understanding & $\mathrm{HIGH}$ & $\mathrm{HIGH}$ & $\mathrm{HIGH}$ \\
\hline
\end{tabular}


The comparison between both programs shows that the property of openness is always important, whatever the issue to be handled in the orchestration of resources. The main problem with the Mirage IV programs relates to the "sensing" phase, which makes the type of the boundary object (bridge and mental models) and the property of completeness more important than the others. The managerial problem with the Rafale program relates to the "seizing" and "reconfiguring" phases. Malleability and granularity are now the most important properties.

Two main aspects of the strategic management of knowledge are also present.

The first one relates to the dynamics of learning processes. Knowledge emerges as the product of interactions between individuals at team (or boundary object) level. It is framed by the questions addressed during the sensing phase ("noises"). The boundary objects improve the perceptive and conceptual filters generating alertness and apperception. During the seizing and reconfiguring phases, interactions lead at the same time to the reduction of transaction costs and to knowledge improvements. Openness, granularity, malleability and completeness contribute to this outcome. Proposition \#2 is relevant.

The second aspect relates to a result introduced by Boisot (1998): knowledge codification can either occur in the abstract or in the concrete. Codification translates into concrete features with a physical boundary object (e.g. Mirage IV scale-1 model) while it requires high levels of abstraction with the digital boundary object generated with 3D CAD software (e.g. Rafale). This aspect does not depend on the purposes of the boundary objects described in the cases, yet it directly impacts the openness, the associated entry costs, the observability of experiments, and the dynamics of teamwork. Propositions \#2 and \#4 should be therefore rephrased along Boisot's developments on "articulation costs", and also expand into managerial recommendations on how to design boundary objects.

\section{Boundary Object, The Orchestration of Resources AND TEAMWORK}

With this comparative case study, we have identified that the impact of boundary objects on the orchestration of resources depends on interactions framed by the presence of the boundary object: team cognition, (team-based) effectiveness of the collective sensemaking process, and team experience. Individuals who interact with the boundary object immerge into a team framed by joint interactions and by transaction costs. Team cognition and team experience support the process of transaction cost minimization that manifests with distance to, and familiarity with the boundary object. "Evolutionary fitness" (Teece's words) depends on the "building blocks" identified by Felin et al (2012): processes, interactions and structures. It shows that the orchestration of resources cannot rely on the sole computation of individual psychologistic descriptions, and on simple aggregations of individuals. It deals with the elaboration of a "cognitive space". Our proposition \#5 proves to be therefore relevant, yet it has to be reshaped in order to take into account the importance of teamwork: the management of the boundary object shows how to analyze the minimization of transaction costs via the management of the team boundaries, and the associated routines.
The analysis of the link between boundary objects and dynamic capabilities shows that the micro-foundations of "sensing", "seizing" and "reconfiguring" remain first and foremost an instance of interactionism, where group- and organization-based "social processes and structures" are at the minimum as much important as the psychology of isolated decision-makers. The ability at installing a link throughout all three phases of the orchestration of resources depends on the co-evolution of knowledge inside the "cognitive space". The substance of teambased cognitive mechanisms also explains how each step in the orchestration of resources will cognitively leverage on the previous ones.

\section{Boundary ObJects Require a Leader, Not ONLY a MANAger}

Numerous contributions have already identified interactions between managers as essential features for the orchestration of resources. The same holds for the reference to a boundary object. How do team-members work around the boundary object? They need a leader. In the Mirage IV and Rafale cases, the leader runs the abstraction process with all teammates. Abstraction and codification are no by-products: contributors to the knowledge process are aware of the necessity of managing these cognitive activities in real time. This leader behaves as a facilitator (Versailles et al, 2015) in charge of highlighting the steps contributing to the elicitation of new knowledge, and to the codification process.

We identify that the manager of the boundary object plays a key role for knowledge articulation, which confirms the relevance of our proposition \#4. We have also identified that the ways of working with the boundary object always required a specific actor to take leadership in the codification of (some) processes and keep the memory of activities (including decisions). The comparison of the Mirage IV and Rafale cases actually points out that the managers in charge of these tasks (or holding these positions) were perfectly aware of the critical importance of their contributions for the programs. In most cases, these managers represented the system integrator, even if they were also actual contributors to all phases themselves.

\section{BOUNDARY OBJECTS AND INTERDEPENDENCIES IN INTEGRATION NETWORKS}

The last result in this contribution links the use of boundary objects and the orchestration of resources to the dynamics of system integration. In both programs, the managers were aware of the importance of the "reconfiguration" phase. This might represent a driver of system integration in the aerospace industry where most companies demonstrate a long-lasting proactive commitment to their ecosystem. Building competences requires a lot of time. The industry did not only "use" the boundary object: they shaped it deliberately as the enabler for the orchestration of resources on the long run. Boundary objects were initially used in order to address issues that were inaccessible to isolated actors; they were used as part of the list of tools available for the joint management of complexity and interdependencies (Brusoni et al, 2001; Versailles, 2005). The comparison between Mirage IV and Rafale points out that the criticality of the boundary objects evolves over time. The cases show that the level of criticality 
linked to the "sensing" did not reduce much over time, but it has proportionally vanished against the rising importance of the contributions to "seizing" and "reconfiguring". This evolution follows the now prevailing importance of digitalization onboard networked complex platforms. Our analysis shows that boundary objects and their managers are key contributors to the overall performance of project management and the orchestration of resources. The description available in this article therefore applies both to similar projects and to integration networks mobilizing at the same time large volumes of different competences. The benefits of using a boundary object, identified in the domain of complex programs, will probably also occur in any domain affected by digitalization.

Yoo et al (2012), or Nambisan et al (2017) clarify digitalization as either the use of digital technology or the outcome of innovation. They explain that digital innovation makes the management of innovation more complex by expanding the number of actors present in the process, and by changing the way to manage exploratory projects. It requires an improved fluidity and an ability to experiment more often and faster. The reference to boundary objects may support the associated ways of working. It offers the opportunity to develop fast prototyping and to interact rapidly with actual users in the actual life. The management of digital innovation is also less stable than in traditional projects: goals, technologies and involved actors can change rapidly, as partly illustrated here in this research. $3 \mathrm{D} C A D$ software as used in the boundary object for the Rafale program may accelerate the projects, or even become the mandatory step towards the management of digitalization. Taking into account the properties of the boundary object identified in the Rafale program (granularity, malleability, and completeness) may help to better define the ways of working on complex projects in the era of digitalization, and improve them.

\section{References}

AdNER, Ron; KAPPORT, Rahul (2010). "Value creation in innovation ecosystems: how the structure of technological interdependence affects firms performance in new technology generations", Strategic management journal, Vol. 31, pp. 306-333

Augier, Mie; Teece, David J. (2009). "Dynamic capabilities and the role of managers in Business strategy and economic performance", Organization Science, Vol. $20 \mathrm{~N}^{\circ}$ 2, pp. 410-421

BArney, Jay B; Felin, Teppo (2013). "What are microfoundations?” The Academy of management perspective, Vol. $27 \mathrm{~N}^{\circ} 2$, pp. 138-155.

BECHкy, Beth A. (2003). "Sharing meaning across occupational communities: the transformation of understanding on a production floor", Organization Science, Vol. $14 \mathrm{~N}^{\circ} 3$, pp. 312-330.

Boisot, Max H. (1998). Knowledge assets. Securing competitive advantage in the information economy. New York: Oxford University Press.

Boisot, Max H.; Canals, Agustí (2004), "Data, information and knowledge: have we got it right?", Journal of Evolutionary Economics, Vol. $14 \mathrm{~N}^{\circ} 1$, pp. 43-67.

Boland, Lawrence A. (2003). The foundations of economic method, A Popperian perspective, London: Routledge, $2^{\text {nd }}$ edition
Brown, John S.; Duguid, Paul (1998). "Organizing knowledge”, California Manag. Review, Vol. $40 \mathrm{~N}^{\circ} 3$, pp. 90-111

Brusoni Stefano; Prencipe, Andrea; Pavitt, Keith (2001). "Knowledge specialization, organizational coupling, and the boundaries of the firm: Why do firms know more than they make?", Administrative Science Quarterly, Vol. $46 \mathrm{~N}^{\circ} 4$, pp. 597-621.

Campbell, Donald T. (1974). "Evolutionary epistemology”, in P. A. Schilpp, ed; The philosophy of Karl R. Popper, La Salle, Ill.: Open Court, pp. 413-463

Capron, Laurence; Mitchell, Will (2009). “Selection capability: How capability gaps and internal social frictions affect internal and external strategic renewal", Organization Science, Vol. 20 $\mathrm{N}^{\circ} 2$, pp. 294.312.

CARlile, Paul R. (2002). "A pragmatic view of knowledge and boundaries: Boundary objects in new product development", Organization Science, Vol. $13 \mathrm{~N}^{\circ}$ 4, pp. 442-455

Dougherty, Deborah (2001). "Reimaging the differentiation and integration of work for sustained product innovation", Organization science, Vol. $12 \mathrm{~N}^{\circ} 5$ pp. 612-631

Eisenhardt, Kathleen M. (1989). "Building theories from case study research", Academy of Management Review, Vol. $14 \mathrm{~N}^{\circ} 4$, pp. 532-550.

Espinosa, J. Alberto; Lerch, F. Javier; Kraut Robert E. (2004). "Explicit versus implicit coordination mechanisms and task dependencies: One size does not fit all" in Eduardo Salas and Stephen M. Fiore (eds.), Team Cognition: Understanding the Factors That Drive Process and Performance. Chapter 6: pp. 107130. US Psychological Association.

Felin, Teppo; Foss Nicolai J.; Jeimeriks, H.; Madsen T. L. (2012). "Microfoundations of routines and capabilities: individuals, processes, structure", Journal of Management Studies, Vol. 49 $\mathrm{N}^{\circ}$ 8, pp. 1351-1374

Felin, Teppo; Foss Nicolai J. (2011). “The endogenous origin of experience, routines and organizational capabilities: the poverty of stimulus", Journal of Institutional Economics, Vol. 7, pp. 231-256.

Fiore, Stephen M.; Schooler, Jonathan W. (2004). "Process mapping and shared cognition: teamwork and the development of shared problem models", chapter 7 pp. 133-152 in Salas and Fiore, eds; 2004.

FONG, Allan; VALERdi Ricardo; SRINIVASAN Jayakanth (2007a). Boundary objects as framework to understand the role of systems integrators. Systems Research Forum. Vol. 2: pp. 11-8.

FONG, Allan; VALERd Ricardo; SRINIVASAN Jayakanth (2007b). Using a boundary object framework to analyze interorganizational collaboration. INCOSE.

Foss, Karen; and Foss, Nicolai J. (2005). "Resources and transaction costs: how property rights economics furthers the resourcebased view." Strategic Management Journal, Vol. $26 \mathrm{~N}^{\circ} 6$, pp. 541-553.

Foss, Nicolai J. (2011). "Why micro-foundations for resource-based theory are needed and what they may look like." Journal of Management, Vol. $37 \mathrm{~N}^{\circ}$ 5, pp. 1413-1428

Fylkelnes, Torgeir Knag (2006). “Abducing abduction.” Logic Journal of the IGPL: Special issue on 'Abduction, practical reasoning, and creative inferences in science', Vol. $14 \mathrm{~N}^{\circ} 2$, March, pp. 179-88. 
Glaser, Barney G.; Strauss, Anselm L. (1967). Discovery of Grounded Theory, Strategy for Qualitative Research. Chicago (IL): Aldine Publishing.

Helfat, Constance E.; Peteraf, Margaret A. (2015). "Managerial cognitive capabilities and the microfoundations of dynamic capabilities", Strategic Manag. Journal, Vol. 36 Nº, pp. 831-50.

Helfat, Constance E.; Finkelstein, Sydney; Mitchell, Will; Peteraf, Margaret A.; Singh, Harbir; Teece, David J.; Winter, Sidney G. (2007). Dynamic capabilities: Understanding strategic change in organizations, London: Blackwell.

Henderson, Rebecca M., Clark, Kim B. (1990). “Architectural innovation: The reconfiguration of existing product technologies and the failure of established firms", Administrative Science Quarterly, Vol. 35 N$^{\circ} 1$, pp. 9-30.

Jansen, Justin J. P.; Tempelaar, Michael P.; Van den Bosch, Frans A.J.; Volberda, Hank W. (2009). "Structural differentiation and ambidexterity: the mediation role of integration mechanisms" Organization Science, Vol. $20 \mathrm{~N}^{\circ}$ 4, pp. 797-811

Kirzner, Israel M. (1979). Perception, opportunity and profit. Studies in the theory of entrepreneurship. Chicago, IL.: University of Chicago Press (1983 paperback edition).

Kor, Yasemin Y.; Mesko, Andrea (2013). "Dynamic managerial capabilities: configuration and orchestration of top executives' capabilities and the firm's dominant logic", Strategic Management Journal, Vol. 34, pp. 233-244.

LEE, Charlotte P. (2005). “Boundary negotiating artifacts: Unbinding the routine of boundary objects and embracing chaos in collaborative work". Computer Supported Cooperative Work. Vol. 16 $\mathrm{N}^{\circ}$ 3, pp. 307-339.

Levina, Natalia; VAast, Emmanuelle (2005). “The emergence of boundary spanning competence in practice: implications for implementation and use of information systems". MIS Quarterly. Vol. $29 \mathrm{~N}^{\circ} 2$, pp. 335-363.

Lorenz, Konrad (1973). Behind the mirror, New York: Harcourt Brace Jovanovich

Marrone, Jennifer A. (2010). “Team Boundary spanning: a multilevel review of past research and proposals for the future", Journal of management, $\mathrm{N}^{\circ} 4$, pp. 911-940.

Mérindol, Valerie; Versailles, David W. (2010). "Dual-use as knowledge-oriented policy: France during the 1990ies and the 2000ies", International Journal of Technology Management, Vol. $50 \mathrm{~N}^{\circ} 1$, pp. 50-98.

Miles, Matthew B.; Huberman, A. Michael (1994). Qualitative data analysis, An expanded sourcebook, London: Sage.

Mohammed, Susan; Dumville, Brad C. (2001). “Team Mental Models in a Team Knowledge Framework: Expanding Theory and Measurement across Disciplinary Boundaries", Journal of Organizational Behavior, Vol. 22, pp. 89-106.

Nambisan S., Lyytinen K., Majchrzak A., S. M. (2017). “Digital Innovation Management: reinventing innovation management research in a digital world". MIS Quarterly, Vol. $41 \mathrm{~N}^{\circ} 1$, pp. 223-238.

Ninniluoto, Ilkka (1999). "Defending abduction", Philosophy of Science, Vol. 66, pp. S436-S451.

Niıniluoto, Ilkka (2007). "Structural rules for abduction”, Theoria, Vol. 60, pp. 325-329.
Petroni, Angelo M. (1991), "L'individualisme méthodologique", Journal des Economistes et des Etudes Humaines, Vol. $2 \mathrm{~N}^{\circ} 1$, pp. 25-62.

Popper, Karl R. (1972). Objective knowledge: an evolutionary approach, Oxford Univ Press

Radnitzky, Gerard; BArtley W. W. (III), (editors) (1987), Evolutionary epistemology, rationality, and the sociology of knowledge, La Salle, Ill.: Open Court.

RenZI, Barbara G.; GuILIo, Napoletano (2011). Evolutionary analogies: Is the process of scientific change analogous to the organic change?, Cambridge Scholars Publishing.

SAlas, Eduardo; Fiore Stephen M. (editors.) (2004). Team Cognition: Understanding the Factors That Drive Process and Performance. US Psychological Association.

SAlas, Eduardo; Goodwin, Gerald F.; Burke, C. Shawn (editors) (2009). Team effectiveness in complex organizations, Crossdisciplinary perspectives and approaches, Routledge.

Sapienza, Harry J.; Autio, Erkko; George; Gerard; Zahra, Shaker A. (2006). "A capabilities perspective on the effects of early internationalization on firm survival and growth", Academy of management review, Vol. $31 \mathrm{~N}^{\circ}$ 4, pp. 914-933.

Sapsed, Jonathan D.; SAlter, Ammon (2004). "Postcards from the edge: local communities, global programs and boundary objects”, Organization Studies. Vol. 25 N9, pp. 1515-34.

Schneckenberg, Dirk; Truong, Yann; Mazloomi, Hamid (2015). "Microfoundations of innovative capabilities: The leverage of collaborative technologies on organizational learning and knowledge management in a multinational corporation" Technological Forecasting and Social Change, Vol. 100, pp. 356-368.

Smith, Wendy K.; Lewis Marianne W. (2011). "Toward a theory of paradox: a dynamic equilibrium model of organizing”, Academy of Management Review, Vol. $36 \mathrm{~N}^{\circ}$ 2, pp. 381-403.

STAR, Susan Leigh (2010). "This is not a boundary object: reflections on the origin of the concept." Science, Technology and Human Values. Vol. $35 \mathrm{~N}^{\circ}$ 5, pp. 601-17.

Star, Susan Leigh; Griesemer, James R. (1989). "Institutional ecology, 'translations' and boundary objects: Amateurs and professionals in Berkeley's Museum of vertebrate zoology”, Social Studies of Science, Vol. 19 N$^{\circ}$ 3, pp. 387-420.

STrauss, Anselm L.; Corbin, Juliet M. (1990). Basics of qualitative research, 2nd ed., Sage.

Swarts, Jason (2004). “Textual grounding: How people turn texts into tools", Journal of Technical Writing and Communication, Vol. $34 \mathrm{~N}^{\circ} 1$, pp. 67-89.

TeEce, David J., (2000). “Strategies for managing knowledge assets: the Role of firm structure and industrial context", Long Range Planning, Vol. $33 \mathrm{~N}^{\circ}$ 1, pp. 35-54.

Teece, David J., (2007). "Explicating Dynamic capabilities: the nature and microfoundations of enterprise performance", Strategic Management Journal, Vol. 28, pp. 1319-1350.

Teece, David J., (2014) "A dynamic capabilities-based entrepreneurial theory of the multinational enterprise, Journal of international business studies, Vol. $45 \mathrm{~N}^{\circ}$ 8, pp. 8-37

Teece, David J.; PISAno, Gary (1994). “The Dynamic capability of firms: an introduction", Industrial and Corporate Change, Vol. $3 \mathrm{~N}^{\circ} 3$, pp. 537-556. 
Thомаs, Gary (2010). "Doing case study: abduction not induction, phronesis not theory.” Qualitative Inquiry, Vol. $16 \mathrm{~N}^{\circ} 7$, pp. 575-582.

Tsoukas, Haridimos; Efi Vladimirou (2001). "What is organizational knowledge?” Journal of Management Studies, Vol. 38 $\mathrm{N}^{\circ}$ 7, pp. 973-993.

Tsoukas, Haridimos (1996). “The firm as a distributed knowledge system: a constructionist approach”, Strategic Management Journal, Vol. 17 (Winter special issue), pp. 11-25.

Versailles, David W. (2005). "Le maître d'œuvre dans les programmes d'armement: de l'émergence à la consolidation des réseaux de connaissances", Revue d'Economie Industrielle, Vol. 112, pp. 83-105.

Versailles, David. W.; Abel, Marie-Helene; Misseri, Veronique; Moulin, Claude (2015). "Digital platforms for the Facilitation of Expert groups characterized as boundary objects". Proceedings of the 19th IEEE CSCWD conference.
Wenger, Etienne; McDermott, Richard; Snyder, William M. (2002). Cultivating communities of practice, Harvard Business School Press.

Wilson, Greg; Hernde, Carl G. (2007). “Boundary objects as rhetorical exigence: Knowledge mapping and interdisciplinary cooperation at the Los Alamos National Laboratory", Journal of Business and Technical Communication, Vol. $21 \mathrm{~N}^{\circ} 2$, pp. 129-154.

YIN, Robert K. (2009). Case study research: design and methods 4th edition, Sage.

Yoo, Y.; Boland, R. J.; Lyytinen, K.; and MajChrzaK, A. (2012). "Organizing for Innovation in the Digitized World. Organization Science, Vol. 23 N5, pp. 1398-1408.

Zollo, Maurizio; Winter, Sydney G. (2002). "Deliberate learning and the evolution of dynamics capabilities", Organization Science, Vol. 13 N³, May-June, pp. 339-351. 